\title{
Newer initiatives in revised national tuberculosis control programme and its current implementation status
}

\author{
Vishal Soyam', Pallavi Boro² \\ ${ }^{1}$ Assistant Professor, Department of Community Medicine, MVJ Medical College and Research Hospital, Bangalore, ${ }^{2} 3 \mathrm{rd}$ year PG Student, \\ Department of Community Medicine, Maulana Azad Medical College and Associated L.N Hospitals, New Delhi
}

\section{A B S T R A C T}

The Revised National Tuberculosis Control programme has continuously innovative and progressive in addressing issues related to Tuberculosis control in India. With the implementation of RNTCP, India has taken huge stride in reduction of mortality and morbidity due to TB. The programme has actively incorporated various new ideas, innovations and information communication technology to curb this menace. These newer initiatives provide unprecedented opportunities to control Tuberculosis more efficiently if it implemented effectively. India has made enormous progress towards TB control through their honest effort. Innovations will effectively leverage India's endeavour. Programme must continue and sustain these efforts to make India TB free.

Access this article online

Website:

http://nepjol.info/index.php/AJMS

DOI: 10.3126/ajms.v6i5.11945

Key words: Newer initiatives, RNTCP, DOTS, Tuberculosis

\section{INTRODUCTION}

In 1993, a revised strategy called DOTS (Directly Observed Treatment Short-course) to control tuberculosis (TB) was pilot tested. As a result of tremendous success in the pilot project, Revised National TB Control Programme (RNTCP) was launched in the country in 1997 with World Health Organization (WHO) recommended DOTS strategy. The program was expanded in a phased manner and by March 2006, entire country had been covered under the programme. ${ }^{1}$ In terms of treatment of patients, RNTCP has been recognized as the largest and the fastest expanding TB control programme in the world. RNTCP is presently being implemented throughout the country. Tuberculosis (TB) continues to be one of the most common infectious causes of morbidity and mortality, which despite being a curable and preventable disease, continues to impose an enormous health and economic burden on India., ${ }^{2,3}$ The RNTCP is based on global scientific and operational guidelines and evidence, and that evidence has continued to evolve with time. As new evidence became available,
RNTCP has made necessary changes in its policies and programme management practices from time to time. ${ }^{2}$ Since RNTCP programme started; there are number of newer initiatives incorporated into the programme to control the Tuberculosis. This paper is highlighting the recent newer initiatives with their current implementation status.

\section{TB BURDEN IN INDIA}

India accounts for more new TB cases annually than any other country in the world. Out of the estimated 8.6 million TB cases that occurred in the world in 2012, 2-2.4 million were in India, with the best case estimate of 2.2 million cases (176 cases per 100,000 population). ${ }^{4}$ India has contributed to approximately $25.5 \%$ of the total global new cases detection during the year 2012 as per the WHO Global Report 2013. The estimated prevalence of TB cases was 2.8 million cases in 2012 equals to 230 cases/lakh populations, accounting for about $23.3 \%$ of the global prevalence. ${ }^{4}$ In 2012, 2.7 lakh deaths occurred in India at a rate of 22 deaths per lakh persons. ${ }^{4}$ As per WHO estimate, TB accounts for $17.6 \%$ 
of deaths communicable diseases and for 3.5\% of all cause mortality. More than $80 \%$ of the burden of tuberculosis is due to premature death, as measured in terms of disabilityadjusted life years (DALYs) lost. ${ }^{6}$ According to WHO estimate, the prevalence of Multi Drug Resistant TB among notified TB patients is $5.3 \%$, among new pulmonary TB patients $2.2 \%$ and among retreatment pulmonary $\mathrm{TB}$ patients $15 \%$. As per WHO, Human Immunodeficiency Virus (HIV) prevalence amongst incident $\mathrm{TB}$ cases is estimated to be $5 \%{ }^{5}$

\section{GOAL OF THE PROGRAMME}

- To decrease mortality and morbidity from TB and

- To interrupt chain of transmission of infection until TB ceases to be a major public health problem in India.

\section{OBJECTIVES OF THE PROGRAMME PROPOSED IN NATIONAL STRATEGIC PLAN ${ }^{7}$}

- Early detection and treatment of at least $90 \%$ of estimated TB cases in the community; including Drug resistant and HIV associated TB.

- Successful treatment of at least $90 \%$ of all new TB patients, and at least $85 \%$ of previously treated TB patients.

- Initial screening of all retreatment smear-positive till 2015 and all smear positive by year 2017, for drug resistant TB and provision of treatment services for MDR-TB patients.

- Offer of HIV counseling and testing for all TB patients and linking HIV infected TB patients to HIV care and support.

- Extend RNTCP services to patients diagnosed and treated in the private sector.

\section{RNTCP ACHIEVEMENTS}

Since its inception, the Programme has initiated over 13.8 million patients on treatment, thus saving more than 2.5 million additional lives. In the year 2013, the RNTCP put $1,416,014$ patients on treatment. ${ }^{8}$ The Programme has consistently maintained the treatment success rate $>85 \%$ and National Strategic Plan (NSP) case detection of 70\% since 2007 after whole country coverage. Treatment success rates have tripled from $25 \%$ in pre-RNTCP era to $88 \%$ presently (2012) and TB death rates have been reduced from $29 \%$ to $4 \%$ during the same period. ${ }^{9}$ In 2012, the NSP case detection rate was $68.4 \%$ and treatment success rate $88 \%$. ${ }^{9}$ There is $42 \%$ reduction in TB mortality rate and 51\% reduction in TB prevalence rate by 2012 as compared to 1990 level. ${ }^{4}$ Tuberculosis prevalence per lakh population has reduced from 465 in year 1990 to 230 in
2012. In absolute numbers, prevalence has reduced from 40 lakhs to 28 lakhs annually. ${ }^{4}$ Tuberculosis incidence per lakh population has reduced from 216 in year 1990 to 176 in 2012. Tuberculosis mortality per lakh population has reduced from 38 in year 1990 to 22 in 2012. In absolute numbers, mortality due to TB has reduced from 3.3 lakhs to 2.7 lakhs annually. ${ }^{4}$

Quality assured diagnostic facilities are available through more than 13,209 Designated Microscopy Centres (DMCs) across the country. To ensure quality of sputum microscopy, external quality assurance is being routinely conducted throughout the country as per a standardized protocol based on international guidelines with all components for ensuring quality by on site evaluation, Panel testing and Blinded Cross-Rechecking (BCRC). Networks of more than 4 lakh (0.4million) DOT providers are available to provide quality assured DOT services. All states are implementing the 'Supervision and Monitoring strategy'. The detailed guidelines, tools and indicators for monitoring the performance from the Primary Health Centre (PHC) level to the national level are available. ${ }^{10} 2,708$ Non Government Organizations (NGOs) collaborations and 13,311 private practitioners (PP) are involved in the programme in different signed schemes under NGO/PP schemes. 319 medical colleges (including private ones) have been involved in RNTCP by the end of Quarter 2 of 2013. Health facilities in government sectors outside Health Ministry have been involved, vi\%. Employee State Insurance (ESI), Railways, Ports and the Ministries of Mines, Steel, Coal, etc. ${ }^{4}$

The Phase II (2006-2012) of the Revised National Tuberculosis Control Programme (RNTCP) has been successful in achieving its objectives. ${ }^{3}$ TB burden (prevalence and mortality) in India has reduced significantly when compared to 1990 levels, and India is on track to achieve the TB related millennium development goals. ${ }^{4}$

\section{TWELFTH FIVE YEAR PLAN - KEY ACTIVITIES PROPOSED}

The vision of the Government of India is for a "TB free India" with reduction in the burden of the disease until it is no longer a major public health problem. ${ }^{1}$ To achieve this vision, the RNTCP has announced "universal access to quality TB diagnosis and treatment for all TB patients in the community" with a target of "reaching the unreached" as its new goal and target in the new National Strategic Plan (NSP) 20122017. ${ }^{3}$ In addition to the continuation of existing activities as per $11^{\text {th }}$ Five Year Plan, the following key activities are proposed during the $12^{\text {th }}$ Five Year Plan for achieving the objectives of RNTCP including universal access: ${ }^{2}$ 
- Ensuring early and improved diagnosis of all TB patients, through improving outreach, vigorously expanding case-finding efforts among vulnerable populations, deploying better diagnostics, and by extending services to patients diagnosed and treated in the private sector.

- Improving patient-friendly access to high-quality treatment for all diagnosed cases of $\mathrm{TB}$, including scaling up treatment for MDR TB nationwide.

- Re-engineering programme systems for optimal alignment with National Rural Health Mission (NRHM) at block level and human resource development for all health staff.

- Enhancing supervision, monitoring, surveillance, and programme operations for continuous quality improvement and accountability for each TB case, with programme based research for development and incorporation of innovations into effective programme practice.

\section{NEWER INITIATIVES}

Programmatic management of drug resistant TB (PIMDT) services

The term "Programmatic Management of Drug Resistant TB" (PMDT) (erstwhile DOTS Plus), refers to programme based MDR TB diagnosis, management and treatment. RNTCP introduced the PMDT services since 2007 to address the MDR TB issue in the country. All the districts in the country have achieved complete geographical coverage by March 2013 and programme is now moving towards universal access to quality diagnosis and treatment of MDR TB patients by gradually extending the opportunity to diagnose early during the treatment of TB. ${ }^{11}$ The programme has taken concrete steps to promote rational use of antiTB drugs; these include the novel initiative of extending universal access to free quality anti-TB drugs across India and the development of a guidance document, popularly called "The Chennai Consensus Statement", for healthcare providers outside the programme settings. ${ }^{12}$ The programme has simultaneously initiated diagnostic and treatment services for the management of MDR TB. These services are considered "Standard of Care" and are an integral component of RNTCP to manage Multiple/Extensively Drug Resistant TB (M/XDR-TB) through the existing programme. ${ }^{4}$ The plan to extend drug susceptibility testing to all smear positive retreatment cases upon diagnosis, and all new cases that are smear-positive early during the first-line anti-TB treatment by 2012 also was achieved. ${ }^{4}$

Policy changes related to the DOTS plus: ${ }^{13}$

- The definition of the MDR suspects has been revised to include 'contacts of MDR cases who are found to be smear positive; besides Category I failures and Category II patients who are smear positive at 4 months or later.

- The existing exclusion criteria for MDR suspects i.e. Age $<15$ years and history of intake of second line drugs for more than 1 month in the past has been withdrawn. A new weight band (16-25 Kgs) has been added for the treatment of the pediatric MDR patients.

- In order to make Category IV regimen more effective it has been decided to replace Ofloxacin with Levofloxacin.

- Guidelines for the management of MDR patients with pregnancy have been finalized.

- Guidelines for the management of Extensively Drug Resistant TB (XDR TB) patients with Category V regimen have been formulated.

In 2013, examination of drug resistant TB (DRTB) suspects recorded $71 \%$ and enrolment of MDR TB patients for treatment recorded $47 \%$ increase compared to the previous year. A total of 1,81,021 DRTB suspects were tested and 20,763 MDR TB cases were put on treatment in $2013 .{ }^{4}$ The RNTCP with support of Centre for Disease Control (CDC) and the $\mathrm{WHO}$; is in the process of undertaking a "National Antituberculosis Drug Resistance Survey" in a representative sample of both newly diagnosed and previously treated sputum smear-positive pulmonary TB cases.

\section{MDR-TB suspect criteria as per current programme guidelines*:14 \\ Criteria A \\ All failures of new TB cases \\ Smear +ve previously treated cases who remain smear +ve at $4^{\text {th }}$ month onwards \\ All pulmonary TB cases who are contacts with known MDR TB case \\ Criteria $\mathrm{B}$ - in addition to Criteria $\mathrm{A}$ \\ All smear +ve previously treated pulmonary TB cases at diagnosis Any smear +ve follow up result in new or previously treated cases Criteria $\mathrm{C}-$ in addition to Criteria B \\ All smear -ve previously treated pulmonary TB cases at diagnosis HIV TB co-infected cases at diagnosis}

*The graded criteria for suspecting MDR TB will be scaled up gradually from criteria A to criteria C. It is expected that all districts in the country would be implementing Criteria B by 2012-2013, and Criteria C by 2015

\section{TB-HIV collaborative activities}

In India TB-HIV collaborative activities between RNTCP and National Acquired Immune Deficiency Syndrome Control Program (NACP) started first time in the year 2001 considering high prevalence of HIV among TB patients. The initial 2007 national framework for joint collaboration between the RNTCP and the NACP promoted selective referral of patients with "high risk" behavior (e.g. truck drivers or sex-workers who were not responding to antiTB treatment) for HIV counselling and testing at the nearest HIV testing centre (Integrated Counselling and 
Testing Centre, ICTC). The framework was revised in 2009 with including provider initiated model as a part of an intensified package. ${ }^{15}$ The package was designed to enhance identification of HIV-infected TB cases, linking to HIV care and support and set the ground for better monitoring and evaluation jointly by the two programmes. TB-HIV intensified package includes:

1) Routine referral of all TB patients for HIV counselling and testing.

2) Provision of Cotrimoxazole Prophylaxis Therapy (CPT) to all HIV-TB Co-infected patients through decentralized delivery through the RNTCP programme.

3) All HIV-infected TB patients must be provided access to care and support for HIV/AIDS, including antiretroviral therapy.

4) Expanded recording and reporting including shared confidentiality of HIV status with TB programme. ${ }^{16}$ The Intensified TB-HIV package was scaled up in the entire country in June 2012. ${ }^{9}$ At the National level TB-HIV coordination committee (NTCC) and National level technical working group (NTWG) regularly monitor and suggest on key policy related to TB/HIV Collaborative activities. The NTWG on TB/HIV decided to implement Provider Initiated Testing and Counselling PITC among presumptive (suspected) TB cases strategy recommended by WHO in all "high" HIV prevalent settings in India (A and B category districts) in a phased manner. ${ }^{4}$ In 2012, out of total registered cases, HIV status of 8,21,807 (56\%) TB patients were known. Of them, about 44,063 (5.3\%) were HIV positive. $92 \%$ of these patients were put on CPT while $74 \%$ of them received ART. ${ }^{9}$ In 2013 , out of total registered cases, HIV status of $887903(63 \%)$ TB patients were known. of them, about 45,999 (5\% of those tested) were diagnosed as HIV positive and were offered access to HIV care. ${ }^{4}$

\section{Three 'I's of HIV-TB:}

1) Intensified TB case finding followed by high-quality AntiTB treatment.

2) Isoniazid Preventive Therapy (IPT).

3) Infection control in HIV care setting.

Intensified TB case finding has been implemented nationwide at all HIV Care centers (at ICTCs and Antiretroviral Treatment (ART) centres). As of December 2013, 410 ART centres, and 871 link ART centres and 158 Link ART plus Centres are operating in the country. In proportion ART and ICTC centres contribute to around $4 \%$ of case finding of the RNTCP. ${ }^{4}$ The cross referral mechanism were started to early diagnosis and co-management shown in Figure 1.
CBNAAT (Cartridge Based Nucleic Acid Amplification Test)

Earlier and improved detection of all types of TB are global priorities for TB control. As conventional laboratory methods are time consuming. ${ }^{17}$ CBNAAT is an automated Cartridge Based Nucleic Acid Amplification Test that has demonstrated its potential to detect tuberculosis and Rifampicin resistance with high accuracy. ${ }^{18} \mathrm{It}$ is also called Gene Xpert MTB/RIF (Cepheid Inc, USA) test, a highly sensitive and specific tool with a quick turn-around time (TAT), offer early diagnosis of TB and DR-TB) in the programmatic settings amongst adult and children as well. ${ }^{19}$

This technology will reduce the TAT from four-six weeks in case of solid culture to two-three weeks in liquid culture, eight hours in LPA (Line Probe Assay) and as less as 2 hours in automated NAAT for diagnosing TB and resistance to Rifampicin. ${ }^{4}$ Automated Nucleic Acid Amplification Test (NAAT) is also under consideration in RNTCP programme. The programme has undertaken a feasibility studies for implementation NAAT under the programme setting in terms of Infrastructure, HR requirements and skills \& External Quality Assurance (EQA) procedures involved. The programme has also developed a guidance document for the use of CBNAAT technology. Currently 80 such CBNAAT machines deployed across the country. ${ }^{4}$

Ban on commercial serology tests for TB diagnosis The Gazette of India, Ministry of Health and Family Welfare (Department of Health and Family Welfare) has notified G.S.R. 432 (E) for prohibiting the import of the commercial sero-diagnostic test kits for tuberculosis and G.S.R. 433 (E) for prohibiting the manufacture, sale, distribution and use of the serodiagnostic test kits for tuberculosis on $7^{\text {th }}$ June,2012. ${ }^{20,9}$ The serological tests are based on antibody response, which is highly variable in TB and may reflect remote infection rather than active disease. The WHO experts Group and Strategic and Technical Advisory Group for Tuberculosis (STAG-TB) which reviewed the data and concluded that currently available commercial serological tests provide inconsistent and imprecise results and put patients lives in danger, therefore WHO strongly recommended that these tests should not be used for the diagnosis of pulmonary and extra-pulmonary TB. ${ }^{21}$ This historic ban has had a big impact in reducing the use of inaccurate serological tests in India. ${ }^{4}$

\section{TB notification}

India's RNTCP provides quality assured diagnostic and treatment services to all the TB patients including necessary supportive mechanisms for ensuring treatment adherence and completion. ${ }^{4}$ However these services cannot be made available to large number of patients availing services from private sector, as they are not currently reported to the 


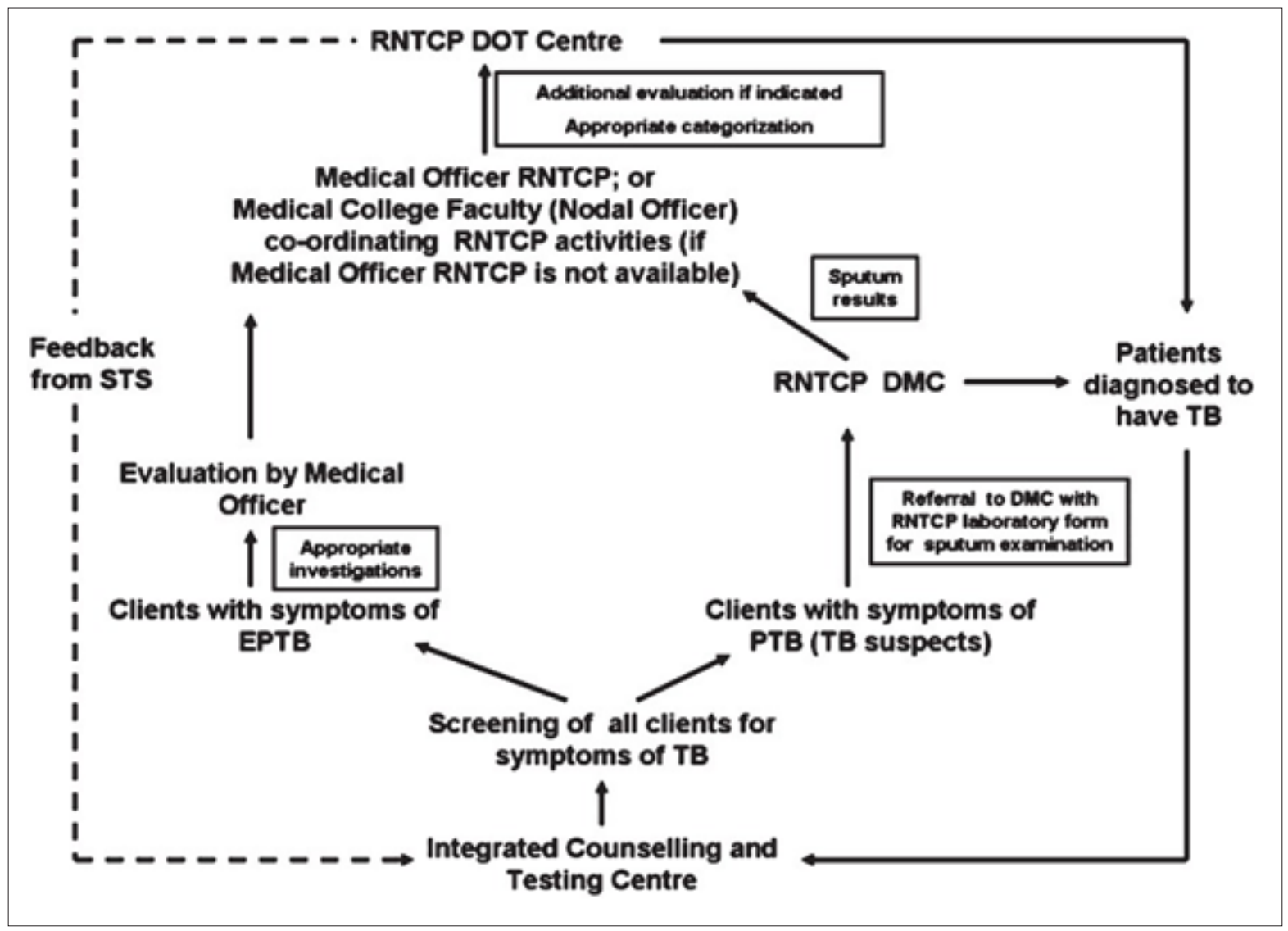

Figure 1: HIV-TB Cross referral mechanism ${ }^{12}$

programme. ${ }^{4}$ The country has a huge private sector and it is growing at enormous pace. Private sector predominates in health care and TB treatment. Poor prescribing practices among private providers with inappropriate and inadequate regimens; and unsupervised treatment without supporting patient for ensuring treatment adherence and completion; inappropriate diagnosis and irregular/incomplete treatment with anti-TB drugs may contribute to complications, disease spread and emergence of DRTB. ${ }^{4}$ In order to ensure proper TB diagnosis and case management, reduce TB transmission and address the problems of emergence and spread of DRTB, it is essential to have complete information of all TB cases. To curb this situation, Government of India declared Tuberculosis a notifiable disease on $7^{\text {th }}$ May 2012 mandating all the healthcare providers to notify every TB case diagnosed and/or treated to local authorities i.e. District Health Officer/ Chief Medical Officer of a District and Municipal health Officer of a Municipal Corporation/Municipality or to the Nodal Public Health Authority (for this purpose) or officials designated by the States/Union Territories for this purpose every month in a given format. ${ }^{22}$ All the health establishments throughout the country in public as well as private and non-governmental sector are expected to notify TB cases. Option of registration and login for private facilities for TB notification indirectly (through email, hardcopy, softcopy and mobile application) in Nikshay will be made available by June $2014 .^{4}$

Sensitization of huge number of private health care providers especially with inadequate human resources, following up notified cases, managing huge information at different levels and creating a national TB register and ensuring duplication is a big challenge. However, with support of various partners like IMA \& CBCI, notification is progressing. ${ }^{4}$

With efforts for sensitization of programme officials \& staff and then subsequently to private sector, the number of private health facilities registered in Nikshay for TB notification increased many fold in 2013 as compared to 2012. A total of $>57,000$ private health facilities are registered till now shown in Figure 2.

With increasing number of health facilities; registered notification of TB cases also increased many fold. Till now $>41,000 \mathrm{~TB}$ cases have been notified by private sector in addition to $\sim 5,000$ cases notified by public sector being treated outside RNTCP shown in Figure 3. Though this is still the beginning and case based surveillance with 


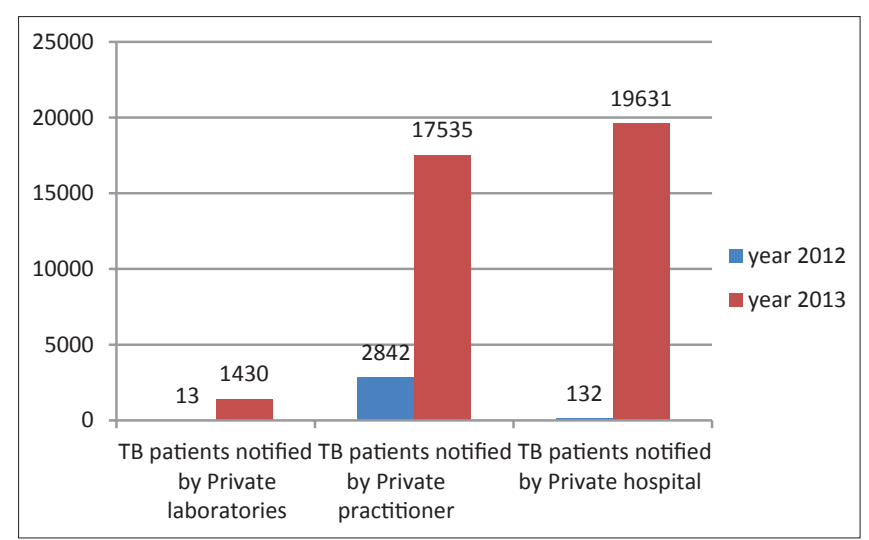

Figure 2: Private facilities registered in year 2012 and 2013

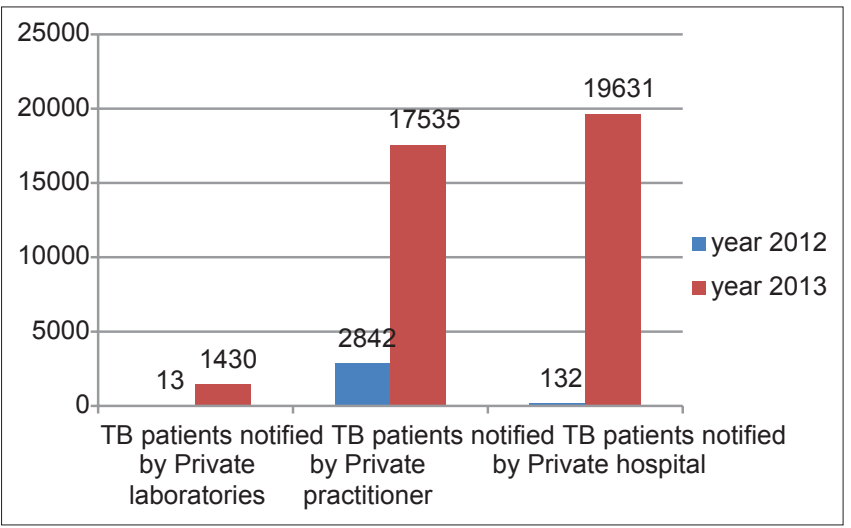

Figure 3: TB notification by private sector in a year 2012 and 2013.

increasingly complete notification by all health facilities across the country will be the milestone for RNTCP in the coming years.

\section{PPIM (Public-Private Mix)}

Innovative PPM schemes have been formulated by the Programme to encourage Non-Governmental Organizations (NGOs), private practitioners, Health Facilities outside Ministry of Health [ESI, Railways, Central Government Health Scheme (CGHS), Ministries of Defense, Steel, Coal, Mines, Petroleum and Natural Gas, Shipping, Power] to encourage their participation and contribution to TB control efforts in the country. ${ }^{23}$ Currently more than 3000 NGOs, 30,000 private practitioners and 150 corporate sector health facilities are involved in the provision of RNTCP services. ${ }^{4}$ Public private mix efforts though beneficial, remain a very small proportion relative to the large numbers of private sector providers; hence the impact of these efforts has so far been relatively limited. ${ }^{24}$ The Indian Medical Association (IMA) is an important partner of RNTCP at national and state levels and are working together to implement the Project and Portfolio Management (PPM) component of a project recently approved by the GFATM (Global Fund to Fight AIDS, Tuberculosis and Malaria). The Central TB Division (CTD) runs Intensified PPM Project in fourteen urban areas in the country. The NSP will seek to engage the private sector using the "Public Private Interface Agency" (PPIA) model. ${ }^{4}$

\section{Involvement of medical colleges}

Systematic involvement of medical colleges under RNTCP has been a huge success story. Under RNTCP, Medical Colleges play important roles in service delivery, advocacy, training and operational research. ${ }^{4}$ They also made contributions in RNTCP policy formulation and programme implementation. Medical Colleges have been effectively organized at large scale through task force mechanism at state, zonal and national level as shown in Figure 4, with RNTCP supporting with additional human resources, logistics for microscopy, funds to conduct sensitization, training and research in RNTCP priority areas.

At present over 330 medical colleges, both public and private have been involved in TB control in India. ${ }^{4}$ They have contributed in a major way in finding more TB cases, especially smear negative and extrapulmonary cases. Medical colleges are contributing to diagnosis and treatment of HIV-TB co-infection and development of laboratory infrastructure for early diagnosis of $\mathrm{M} / \mathrm{XDRTB}$ and DOTS-Plus sites for treatment of MDR-TB cases. ${ }^{25}$ Overall, at a national level, medical colleges have contributed to $25 \%$ of TB suspects referred for diagnosis; $23 \%$ of 'new smear-positives' diagnosed; $7 \%$ of DOT provision within medical college; and $86 \%$ treatment success rate among new smear-positive patients. ${ }^{12}$ In 2013, the medical colleges diagnosed a total of 214330 TB cases including 95450 Sputum PositivePulmonary, 40680 Sputum Negative Pulmonary and 78200 Extra Pulmonary TB cases. ${ }^{4}$

\section{Diabetes screening}

The pilot is being conducted in 14 sites across the country in 2011, on the basis of results of pilot study in 2012, the policy decision was taken to screen all TB patients for DM in the 100 districts where National Programme for Prevention and Control of Cancer, Diabetes, Cardiovascular Diseases and Stroke (NPCDCS) activities are being implemented. ${ }^{1,9}$ The programme is looking forward to country wide scale up of this initiatives.

\section{Indian standards for TB care}

All patients with TB should receive the same quality of care, based on the best evidence available. Therefore, International Standard for TB care (ISTC) developed in 2006 with 17 standards. Subsequent revision was done, upgraded to 21 standards in $3^{\text {rd }}$ revision and published in March 2014. RNTCP conforms to the standards prescribed in ISTC. 1,26,27 Coinciding with the World TB Day on 24 March 2014, the Government of India released Standards for TB Care in India (STCI), a path-breaking initiative, to introduce uniform 


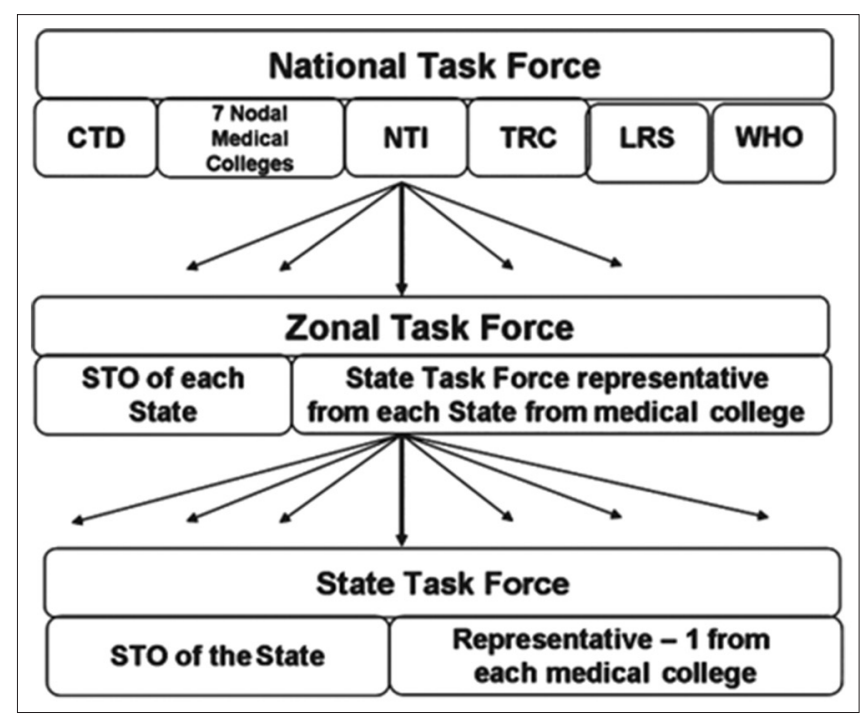

Figure 4: Structure of medical college involvement in RNTCP: CTD, Central TB Division; NTI, National Tuberculosis Institute, Bengaluru; LRS, Lala Ram Swarup Institute of Tuberculosisand Respiratory Diseases; TRC, Tuberculosis Research Centre [presently known as National Institute for Research in Tuberculosis (NIRT)], Chennai; STO, State Tuberculosis Officer; (Adopted from Sharma SK et al) ${ }^{12}$

standards for TB care in all sectors. Total 26 standards were developed and country-based evidence is listed for each of the standards in this document. This includes a new set of standards for social inclusion. ${ }^{28}$

Case-based web-based reporting system (NIKSHAY) The database of RNTCP was conventionally on Epiinfo based software for reporting with electronic data transmission from district level upwards. Initially DOS version was in use and the programme shifted to windows version in $2007 . .^{29}$ The digitization of information being an ongoing process, the generation of data in aggregated form and report submission is currently being done on quarterly basis. This causes a delay of more than three months and loss of case based data. To address this gap, CTD in collaboration with National Informatics Centre (NIC) developed a case based web-based online (Cloud) application - 'Nikshay', launched in May 2012, which has been now scaled up nationally. It has following components ${ }^{4}-$

- Master management

- User details

- TB patient registration \& detail of diagnosis, DOT provider, HIV status, follow up, contact tracing, outcome

- Details of Solid and liquid culture \& Drug Sensitivity Testing (DST), Luciferin Probe Assay (LPA), CBNAAT

- DRTB patient registration with details

- Referral \& transfer of patients

- Private health facility registration and notification
- Mobile application for TB notification

- SMS alert to patients on registration and to programme officer

- Automated periodic report (case finding, sputum conversion and outcome).

Since implementation in last two year, till recently (March 2014) over 2.3 million patients including MDR cases have been registered in Nikshay. By October 2013, 56,000 private health facilities have been registered and more than 34,000 TB patients notified by these private health facilities have been registered in Nikshay. Details of more than 5,800 contractual staff have also been entered. Nikshay was honored with National e-Governance award (Gold) 2013-14 during the National Conference on e-Governance held at Kochi on 30-31 January, 2014. ${ }^{4}$

\section{Universal access to TB care}

One of the major policy decision were taken by RNTCP in 2010 was "Universal access to TB care" to address one of the major reasons for death in TB patients is late diagnosis. All TB patients in the community to have access to early, good quality diagnosis and treatment services in a manner that is affordable and convenient to the patient in time, place and person.

\section{FUTURE PLANS}

- Use of LED-based microscopy for sputum smear examination and its expansion phase wise manner.

- Institution of air-borne infection control measure mandatory for upcoming college; modifications to be made in existing colleges.

- Setting up of more DOTS-Plus sites in medical colleges for providing treatment for M/XDR-TB.

- Capacity building in research methodology and proposal writing for medical college faculty.

- Initiating nation-wide Operational Research (OR) studies into relevant areas e.g. TB-Diabetes mellitus.

\section{REFERENCES}

1. Central TB Division, MOHFW, GOI. TB India 2012 status report. http://tbcindia.nic.in/pdf/TB\%20India\%202012-\%20Annual\%20 Report.pdf. Retrieved 10/05/13.

2. Gupta RS. Update on Revised National Tuberculosis Control Programme. Indian J Tuberc. 2014 Jan;61(1):30-4.

3. Sachdeva KS, Kumar A, Dewan P, Kumar A, and Satyanarayana S. New Vision for Revised National Tuberculosis Control Programme (RNTCP): Universal access - "Reaching the un-reached". Indian J Med Res May 2012; 135(5): 690-4.

4. Central TB Division, MOHFW, GOI. TB India 2014 RNTCP Annual Status Report. www.tbcindia.nic.in/pdfs/TB\%20 INDIA\%202014.pdf. Retrieved 11/05/14. 
5. World Health Organization. Global Tuberculosis Report 2013. Available at www.who.int/iris/ bitstream/10665/91355/1/9789241564656_eng.pdf. Retrieved 11/12/14.

6. Central TB Division, MOHFW, GOI. TB India 2012 status report. http://tbcindia.nic.in/pdf/TB\%20India\%202012-\%20Annual\%20 Report.pdf. Retrieved 12/12/13.

7. Universal access to TB Care- A practical guide for programme managers. New Delhi: Central Tuberculosis Division, Directorate General of Health Services, Ministry of Health \& Family Welfare; 2010.

8. Central TB Division (2011). Official website of the Revised National TB Control Programme, Directorate General of Health Services, Ministry of Health \& Family Welfare, Government of India. Available from: www.tbcindia.org. Retrieved 28/02/2011.

9. Central TB Division, MOHFW, GOI. TB India 2013 RNTCP Annual status report. www.tbcindia.nic.in/pdfs/tb\%20india $\% 20$ 2013.pdf

10. Strategy document for the supervision and monitoring of the Revised National Tuberculosis Control Programme. New Delhi: Central Tuberculosis Division, Directorate General of Health Services, Ministry of Health \& Family Welfare, Government of India; 2005

11. MOHFW, RNTCP Guidelines on programmatic management of drug resistant TB (PMDT) in India, MOHFW, New Delhi 2012.

12. Sharma SK, Mohan A, Chauhan LS, Narain JP, Kumar P, Behera $D$ et al. Contribution of medical colleges to tuberculosis control in India under the Revised National Tuberculosis Control Programme (RNTCP): Lessons learnt \& challenges ahead. Indian J Med Res. February 2013; 137: 283-94.

13. MOHFW RNTCP. Guidelines on programmatic management of drug resistant TB (PMDT) in India, MOHFW New Delhi 2012.

14. Tbcindia.nic.in [Internet]. RNTCP Response to Challenges of Drug resistant TB in India; 2012. http://www.tbcindia.nic.in/pdfs/ RNTCP\%20Response\%20DR\%20TB\%20in\%20India\%20-\%20 Jan\%202012\%20update.pdf Retrieved 14/11/2014.

15. National Framework for Joint HIV/TB Collaborative Activities October 2009. Delhi: CTD, NACO and MOHFW publication. p29. http://www.tbcindia.org. Retrieved 29/06/2011.

16. RNTCP Performance report 2010. Delhi: State TB cell; 2011. http:// www.Dotsdelhi.org/newsletter2011.php. Retrieved 28/06/2011.

17. World Health Organization. The Stop TB Department (2010). Roadmap for rolling out Xpert MTB/RIF for rapid diagnosis of TB and MDR-TB.

18. Raizada N, Sachdeva KS, Sreenivas A, Vadera B, Gupta RS, Parmar $\mathrm{M}$ et al. Feasibility of decentralised deployment of Xpert MTB/RIF test at lower level of health system in India. PLoS One. 2014 Feb 26;9(2):e89301.

19. Boehme CC, Nabeta P, Hillemann D, Nicol MP, Shenai S, Krapp F, et al. Rapid Molecular Detection of Tuberculosis and Rifampin Resistance. N Engl J Med. 2010 sep 9;363: 1005-15.

20. Central TB Division, MOHFW, GOI. http://www.tbcindia.nic.in/ pdfs/TB $\% 20$ Notification $\% 20$ Govt $\% 20 \% 20$ Order $\% 20$ dated $\% 20$ 07\%2005\%202012.pdf. Retrieved 28/06/2014.

21. World Health Organization. "WHO warns against the use of inaccurate blood tests for active tuberculosis", Geneva, WHO, 2011. www.who.int/mediacentre/news/releases/2011/Retrieved $15 / 08 / 2014$

22. Ministry of Health and Family Welfare. Guidance for TB Notification in India, 2012. http://tbcindia.nic.in/pdfs/ Guidance \%20tool\%20for\%20TB\%20notification \%20in \%20 India\%20-\%20FINAL.pdf. Retrieved 23/04/2014.

23. Agarwal SP, Sehgal Shruti, and Lal SS. Public-Private Mix in the Revised National TB Control Programme. www.tbcindia.nic.in/ pdfs/Tuberculosis\%20Control\%20in\%20India15.pdf. Retrieved 12/02/2012.

24. Lal SS, Sahu S, Wares F, Lonnroth K, Chauhan LS, and Uplekar M. Intensified scale-up of public-private mix: a systems approach to tuberculosis care and control in India. Int J Tuberc Lung Dis 2011; 15: 97-104.

25. MOHFW National programmes under NRHM, annual report 2012-13, MOHFW, Govt. of India New Delhi 2013. 94-104.

26. Hopewell PC, Pai M, Maher D, Uplekar M,and Raviglione MC. International standards for tuberculosis care. Lancet Infect Dis Nov 2006; 6(11): 710-25.

27. Pai M, Satyanarayana1 S and Hopewell P. Improving quality of Tuberculosis care in India. Indian J Tuberce. 2014; 61:12-18.

28. WHO India. Standards for TB care in India. New Delhi. 2014. http://www.searo.who.int/india/mediacentre/events/2014/stci_ book.pdf. Retrieved 12/11/2014.

29. MOHFW National programmes under NRHM, annual report 2012-13, MOHFW, Govt. of India New Delhi 2013. 94-104.

30. Universal access to TB care A Practical Guide for programme managers. http://tbcindia.nic.in/pdfs/Universal_accessto_TB_ Care.pdf. Retrieved 16/11/2014 